R O C ZNIKI HUMAN IS T Y C Z N E

Tom LXVIII, zeszyt 5 - 2020

ZESZYT SPECJALNY / SPECIALE UITGAVE

DOI: http://dx.doi.org/10.18290/rh20685sp-7

AGATA KOWALSKA-SZUBERT

\title{
GIJ ZULT ANDERMANS TAALFOUTEN KOESTEREN! TOLERANTIE VOOR TAALVERANDERINGEN EN SPELLINGFOUTEN
}

\begin{abstract}
A b stract. Dit essay is een pleidooi voor zorgvuldiger taalgebruik met name door docenten en vertalers Nederlands. Met name de spelling blijkt altijd weer een lastig struikelblok te zijn, en dat lang niet alleen voor tweede- of vreemdetaalleerders. Het essay gaat in op de problematiek van samengestelde woorden en fouten die bij het wel of niet aaneenschrijven van deze woorden worden gemaakt door professionele taalbeoefenaars van het Nederlands.
\end{abstract}

Trefwoorden: spelling; Kollewijn; samengestelde woorden; spellingfouten; enquête.

\section{TER INLEIDING}

Dat de spelling altijd weer moeilijk blijkt, is al jaren, ja zelfs eeuwen bekend. Men denke bijvoorbeeld aan het bekende opstel Onze lastige spelling van Kollewijn. Dat regels kunnen veranderen, weet iedere taalkundige die de geschiedenis van het Nederlands enigszins volgt. Aan de ene kant bestaat sinds 1954 het 'Groene Boekje', de officiële Woordenlijst van de Nederlandse taal. Aan de andere kant zijn er heel wat artikelen, essays en commentaren geschreven over waarom deze officiële spelling 'niet deugt'; er zijn alternatieve bewerkingen ontstaan of zelfs hele bewegingen (te denken valt aan de aanhangers van de zogenaamde 'witte spelling' die rond het Ge-

Dr. habil. Agata Kowalska-Szubert is verbonden aan de Katedra Filologii Niderlandzkiej (Vakgroep Nederlandse Filologie) van de Uniwersytet Wrocławski (Universiteit van Wrocław). Naast haar universitaire taken is ze ook beëdigde vertaalster/tolk voor het Duits en Nederlands. Haar dissertatie De kool en de geit wordt vaak geciteerd en zette de toon voor haar verdere werk dat vooral gericht is op onderzoek naar ontleningen uit het Nederlands in het Pools. Zij nam deel aan een serie lexicale en fraseologische projecten. Correspondentieadres: Katedra Filologii Niderlandzkiej, Uniwersytet Wrocławski, ul. Kuźnicza 21-22, 50-138 Wrocław, Polen; e-mail: agata. kowalska-szubert@uwr.edu.pl. ORCID: https://orcid.org/0000-0002-5690-7053. 
nootschap Onze Taal zijn verenigd). En ten derde leidt de taal een zelfstandig leven, waardoor er ook tendensen ontstaan die aan de eisen van geen van de voornoemde - laten we ze zo noemen - spellingnormen voldoen.

Soms vloeien die tendensen uit het gewone taalgebruik voort: woorden raken verouderd en maken plaats voor nieuwe woorden en/of constructies die eerder niet bestonden; sommige taalfouten blijken zo vaak voor te komen dat zij op den duur de eerdere norm gaan vervangen. Soms worden nieuwe verschijnselen veroorzaakt door externe factoren zoals een alomtegenwoordige expansie van een vreemde taal. Dit laatste verschijnsel is recent van enorm belang. Het Engels verovert niet alleen de meeste wetenschappelijke velden van Europa ${ }^{1}$ maar sluipt stiekem ook andere talen binnen. In mijn moedertaal, het Pools, manifesteert zich dat vooral in de vorm van ontelbare ontleningen. Het Nederlands is daarnaast vanwege zijn nauwe verwantschap met het Engels op allerlei vlakken intensiever blootgesteld aan verdergaande invloeden (woordvolgorde, idiomatiek, ...). Dus niet alleen de woordenschat als zodanig wordt beïnvloed; het Engels dringt ook door in de Nederlandse zinsbouw of zelfs in de morfologie. Zo wordt steeds meer zichtbaar dat ook de spelwijze van de Nederlandse samenstellingen onder grote druk komt te staan.

\section{HET GROENE BOEKJE EN DE WITTE SPELLING}

Al het allereerste Groene Boekje van 1954 heeft een zekere spellingvrijheid toegelaten; naast de aanbevolen spellingwijze bestond er toen nog de zogenaamde 'toegelaten spelling', die eveneens werd geaccepteerd. De wijzigingen in de spellingnormen die bij de herziening van Groen Boekje in 1995 in het leven traden, hebben de toegelaten spelling als het ware afgeschaft, of tenminsten zeer beperkt. Voortaan zou er één norm gelden; de afwijkingen van deze norm zouden als 'spellingfouten' worden beschouwd. Bij wijze van een protest tegen deze strenge regeling is de zogenaamde 'witte spelling' ontstaan, wat soepeler en met her en der aangepaste paradigmata ten opzichte van het Groene Boekje. Opmerkelijk is dat vrijwel alle Nederlandse kwaliteitskranten als de NRC of De Volkskrant deze 'witte spelling' gebruiken. Maar zelfs de scheppers van de 'witte spelling' hebben

\footnotetext{
${ }^{1}$ Voor vrijwel alle domeinen van de wetenschap is het Engels al een geruime tijd de lingua franca. Echter kan het als een signum temporis beschouwd worden dat Nederlandstalige neerlandici nu ook steeds vaker over het Nederlands in het Engels publiceren, en dat Poolse polonisten dit ook met betrekking tot het Pools plegen te doen, waarbij ze lang niet de enigen zijn.
} 
vermoedelijk in hun stoutste dromen niet voorzien dat op den duur ook de spelling van samengestelde Nederlandse woorden onder druk zou komen te staan.

\section{DE CASUS}

De aanleiding voor dit essay en het onderzoek dat erachter schuilgaat, was de oproep voor het $20^{\mathrm{e}}$ Colloquium Neerlandicum dat in de zomer van 2018 in Leuven werd georganiseerd. De Internationale Vereniging voor Neerlandistiek organiseert om de drie jaar een wereldcongres van neerlandici. Neerlandici, dus mensen van 'intra en extra muros', die zich beroepshalve met het Nederlands bezighouden, bij wie het voornamelijk gaat om (al dan niet) universitair geschoolde en/of werkzame docenten Nederlands en om onderzoekers zowel op het gebied van de literatuur- als taalkunde.

In de boven vermelde oproep om bijdragen te leveren, stond onder meer de volgende passage: "Onderzoek in beweging is een RONDE TAFELGESPREK met vier mensen, op een vast deel van de dag" ${ }^{2}$ (IVN. $20^{\mathrm{e}}$ Colloquium Neerlandicum). Volgens het Groene Boekje moet het echter rondetafelgesprek zijn, of hooguit ronde-tafelgesprek. De spatie tussen ronde en tafelgesprek doet de lezer vermoeden dat het niet om een ronde tafel gaat, maar om een rond gesprek (vergelijk ook het verschil tussen oude mannenhuizen en oudemannenhuizen).

Er zou niets bijzonder opvallends aan deze formulering zijn geweest - de taal leeft en verandert immers, en Nederlandstaligen staan bekend om hun tolerante opstelling tegenover veranderingen - als deze tekst niet door beroepsbeoefenaars aan andere beroepsbeoefenaars was gericht. De taal mag best worden aangepast, maar er is toch een bijzondere verantwoordelijkheid aan de kant van de mensen die met de taal werken. De grote populariteit van het (intussen afgeschafte) Groot Dictee der Nederlandse Taal berustte immers erop dat Nederlandstaligen graag zo correct willen schrijven. Dit geldt in een nog sterkere mate voor wie het Nederlands het werktuig is om er zijn/haar brood mee te verdienen. Deze personen (en dus onderwijzers, leraren/docenten en ook vertalers) worden geacht correct Nederlands te schrijven. De bestaande norm dient als richtlijn voor foutloos taalgebruik, zolang die norm althans niet door een nieuwe is vervangen. En de norm die op dit moment met betrekking tot het schrijven van samengestelde Nederlandse

\footnotetext{
${ }^{2}$ De benadrukking komt van de auteur dezes.
} 
woorden geldt, is: samenstellingen schrijft men als één woord. Om de leesbaarheid te bevorderen kan men bij meervoudige samenstellingen tussen het eerste en het tweede lid van een samenstelling een koppelteken plaatsen.

Wanneer er een congres voor neerlandici wordt georganiseerd, mag ervan uit worden gegaan dat de congresteksten ook door neerlandici zijn geschreven (of op z'n minst gereviseerd). En dus kwam de zin over de 'ronde tafelgesprekken' vermoedelijk van de pen van een neerlandicus/neerlandica. Deze constatering leidde tot de volgende vragen:

(1) Schrijven vakbeoefenaars van het Nederlands dit type samenstellingen vaak verkeerd?

(2) Merken vakbeoefenaars Nederlands verkeerd uit elkaar geschreven samenstellingen op?

en verder:

(3) Hoe tolerant zijn vakbeoefenaars Nederlands ten opzichte van de verkeerde spelling van samenstellingen?

Om antwoorden op de bovenstaande vragen te krijgen, heeft de auteur een enquête georganiseerd, waarbij vooral vakbeoefenaars van het Nederlands benaderd zijn.

\section{DE ENQUÊTE EN DE RESULTATEN ERVAN}

Op Facebook zijn er twee groepen te vinden voor (voornamelijk Nederlandse) tolken/vertalers en leraren, te weten Vertalerskoffiehoek en Leraar Nederlands. De eerste groep verbindt personen die vertalers Nederlands zijn - het gaat om de mensen die zowel vanuit als naar het Nederlands vertalen en van wie de moedertaal niet per se het Nederlands hoeft te zijn; wel moet een deelnemer als vertaler met deze taal werkzaam zijn. Op het moment dat de enquête werd gehouden, telde de Vertalerskoffiehoek 2689 leden.

De naam van de tweede groep, Leraar Nederlands, spreekt voor zich. De leden van de beide groepen (op het tijdstip van het onderzoek waren het er 11432) werken met het Nederlands en zijn bijzonder verantwoordelijk voor de verzorgde omgang met taal:de eersten als leveranciers van een taalproduct, de anderen als docenten, mensen van wie het afhangt hoe de volgende generaties het Nederlands zullen spreken en schrijven.

De enquête werd gehouden onder de deelnemers van beide groepen. De resultaten ervan mogen echter niet als statistisch uitgewogen gegevens worden beschouwd, en wel om de volgende reden: de groep die op de enquête 
heeft gereageerd, was niet consistent; het ging in feite om twee deelgroepen (vertalers en leraren) die bovendien in ongelijke mate door Nederlanders en Vlamingen werden vertegenwoordigd. De conclusies die aan het einde van dit stuk worden gepresenteerd, kunnen dus niet echt als significant gelden. Desondanks mogen ze naar mijn mening wel als een indicator van deproblematiek worden gezien.

In totaal kwamen er 174 antwoorden binnen; 147 daarvan waren geleverd door Nederlanders, 19 door Vlamingen en 8 door anderstaligen. Er waren 108 vertalers en 109 leraren (er waren meerdere opties mogelijk; wie vertaler X-NL en vertaler NL-X was (X staat hier voor een willekeurige andere taal), kon dat afzonderlijk aanvinken. Er waren ook drie afzonderlijke categorieën leraren: leraar NT1, leraar NT2 en leraar NVT.

Wat het geslacht betreft, hebben 150 respondenten het antwoord 'vrouw' en 21 het antwoord 'man' aangevinkt; de drie overgebleven personen hebben dit niet gemeld. De meeste respondenten ( 50 personen) waren in de leeftijdscategorie 26-35 jaar.

Naast algemene vragen naar de nationaliteit, het geslacht en de moedertaal werden de bevraagden in het eerste deel van de enquête verzocht de correcte spelling aan te wijzen. Het ging om een keuze tussen:

- ronde tafelgesprek

- rondetafel gesprek

- ronde-tafelgesprek

- rondetafelgesprek

- ronde tafel gesprek

Er waren meerdere antwoorden mogelijk. De bevraging het volgende resultaat op:

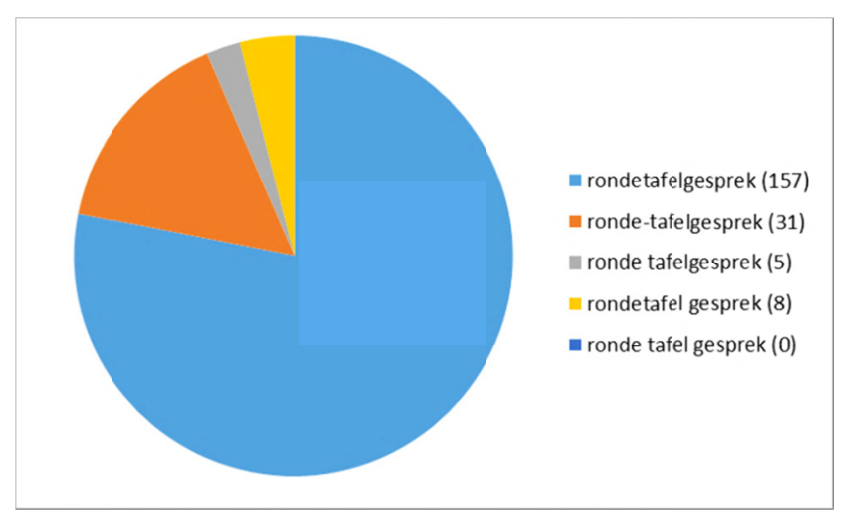


Dat kan als een hoopgevend antwoord worden beschouwd als je bedenkt dat de correcte spelling (rondetafelgesprek) en de toegelaten spelling (rondetafelgesprek) ruim $93 \%$ van alle antwoorden uitmaakte. Interessant is echter ook de indeling in de beroepsgroepen. Het waren uitsluitend leraren die voor de versie ronde tafelgesprek pleitten, terwijl het antwoord rondetafel gesprek meestal (7/8) door vertalers werd gegeven. Geen enkele Nederlander koos de optie ronde-tafelgesprek; dit was in feite het domein van Vlamingen en anderstaligen.

De splitsing van de antwoorden naar het beroep van de respondenten ziet er als volgt uit: 65 vertalers hebben een correct antwoord gekozen (van hen 61 rondetafelgesprek en 4 ronde-tafelgesprek), tegenover 67 leraren (met respectievelijk 64 en 3 antwoorden). Geen enkele vertaler koos voor ronde tafelgesprek of rondetafel gesprek, terwijl respectievelijk 2 en 1 lera(a)r(en) dat deden

De volgende vraag was bedoeld om te checken of de bevraagden het konden waarnemen als woorden onterecht aan of uit elkaar worden geschreven. De vraag luidde als volgt:

"Het reactie vermogen van iedere homosapiens is anders." - Is deze zin correct gespeld?

$-\mathrm{Ja}$

- Nee, er zit één spelfout in

- Nee, er zitten twee spelfouten in

De overgrote meerderheid (131 respondenten) hebben terecht twee spellingfouten gevonden - reactie vermogen en homosapiens. 42 mensen vonden maar één fout. Er was ook één persoon die deze zin helemaal correct heeft gevonden. Opnieuw hadden de Vlamingen helemaal gelijk. Onder de 43 personen die de zin verkeerd hadden beoordeeld, waren er 41 Nederlanders en 2 anderstaligen, daaronder 12 vertalers en 31 leraren.

De derde vraag had betrekking op een bewuste receptie van fouten.

Als $u$ een tekst LEEST:

- bemerkt u dan automatisch meteen alle gevallen van onterecht uit elkaar geschreven woorden (98 reacties)

- bemerkt u dan automatisch sommige onterecht uit elkaar geschreven woorden (69 reacties)

- let u daar dan meestal helemaal niet op (2)

- bemerkt u de onterecht uit elkaar geschreven woorden alleen als u er extra aan aandacht aan besteedt (1 antwoord)

- ziet u meestal geen spelfouten (4 antwoorden). 
De meest interessante constatering vond ikzelf “... let $\mathrm{u}$ er meestal niet op", vooral met betrekking tot de leraren. De twee personen die dit antwoord gaven, waren 1 vertaler (een Nederlandse in de leeftijd 46-55 jr.) en 1 leraar NT1 (een Nederlandse, jonger dan 26 jaar). Terwijl een vertaler dit in principe nog mag doen, vind ik dit bij een leraar toch geen goed teken.

De volgende vraag had betrekking op de vaardigheid eigen fouten te vinden.

Als u een tekst SCHRIJFT:

- maakt u vrijwel nooit fouten in het uit/aan elkaar schrijven van woorden/ woorddelen (gekozen door 42 respondenten);

- maakt $\mathrm{u}$ wel eens een dergelijke fout maar die verbetert $\mathrm{u}$ die ook meteen ( 82 reacties);

- komt het wel eens voor dat u een dergelijke zelf gemaakte fout helemaal over het hoofd ziet ( 47 reacties);

- dit is het laatste probleem dat $\mathrm{u}$ met de Nederlandse spelling hebt (3 keer gekozen).

Vermeldenswaard is hier dat 1 vertaalster en 1 lerares die stelden nooit fouten te maken, maar één fout in de homo-sapienszin hebben ontdekt.

De vijfde vraag betrof de persoonlijke opstelling van de respondenten ten opzichte van het verschijnsel dat ook wel 'spatieziekte' of 'Engelse ziekte' wordt genoemd, namelijk foutief spatiegebruik bij Nederlandse samenstellingen. De mogelijke antwoorden waren:

- Ik zie die als een verengelsing, en dus verloedering van het Nederlands (52 antwoorden).

- Ik vind alle fouten in de spelling erg maar maak geen onderscheid tussen erge en minder erge fouten (46 antwoorden).

- Woorddelen uit elkaar schrijven vind ik minder vervelend dan d/tfouten (59 antwoorden).

- Het is maar een zekere ontwikkelingslijn in de taal, en als zodanig is het helemaal niet erg (17 antwoorden).

- Laat de mensen toch eens schrijven zoals ze willen! ( 0 antwoorden).

Geen enkele respondent was dus van mening dat de spelling niet geregeld hoeft te zijn. In ieder geval is er dus geen sprake van enige tolerantie voor chaos in de spelling. Wat de reacties echter interessant maakt, is het feit dat zowel de voornoemde lerares als vertaalster beiden stelden dat de Engelse ziekte een verloedering van het Nederlands zijn.

De volgende vraag betrof de tolerantie voor de taalfouten over het algemeen. Men kon kiezen tussen: 
- Ik verbeter de fouten alleen beroepshalve. In mijn privéleven doe ik of ik die niet had bemerkt (141 antwoorden)

- Ik maak geen fouten en tolereer ze niet bij anderen (22 antwoorden)

- Laat iedereen zijn eigen fouten maken; anders leren ze nooit (11 antwoorden).

Uit het bovenstaande blijkt dat de overgrote meerderheid (81\%) een grote tolerantie voor taalfouten in het dagelijks leven declareert; dit geldt echter niet voor de beroepscontext. Van de bevraagden wijst 13\% (22 personen) elke vorm van tolerantie af, zowel voor zichzelf als voor anderen. De resterende 6\% (11 personen) stelt zich altijd en overal tolerant op. Nota bene, doet de vertaalster van daarnet of ze de fouten van anderen niet bemerkt en maakt de voornoemde lerares naar haar zeggen zelf geen fouten en tolereert ze ook geen fouten van anderen.

De voorlaatste vraag in de enquête betrof een definitie van taalfouten. De antwoorden waren:

- ze zijn een absoluut normaal verschijnsel, iedereen maakt ze (135 antwoorden)

- ze zijn een bewijs van de slordigheid van de mens (30 antwoorden)

- ze maken de taal rijker en dragen bij tot haar ontwikkeling ( 9 antwoorden).

De respondent stellen zich dus globaal (78\%) tolerant op tegenover taalfouten, en 5\% (9 antwoorden) van de groep verwelkomt ze enthousiast. De overige 17\% (30 antwoorden) keurt taalfouten af. Zowel de vertaalster als de lerares behoren tot de neutrale, en dus tolerante groep.

De laatste vraag luidde als volgt:

Als u iemand gebrekkig (wel verstaanbaar) Nederlands hoort spreken,

- ... spreekt u ook Nederlands.

- ...gaat u liever naar het Engels over.

161 van de respondenten besloten bij het Nederlands te blijven, terwijl 13 zeiden liever naar het Engels over te gaan. Dit kan van een vrijwel grote tolerantie met betrekking tot de fouten getuigen die door buitenlanders worden gemaakt. Een zekere verontrusting wekt echter de samenstelling van de groep die liever naar het Engels overgaat. Voor deze optie hebben 5 vertalers gepleit en liefst 8 leraren Nederlands, daarvan 5 leraren NT1 en 3 leraren NVT. 


\section{CONCLUSIES}

De groep Vlaamse respondenten die de enquête wilden beantwoorden, was duidelijk kleiner dan de groep Nederlanders. Toch is opvallend dat de Vlamingen nog altijd de regel lijken toe te passen dat samenstellingen ook met een koppelteken mogen worden geschreven als dit voor de lees- en verstaanbaarheid van de samenstelling bevorderend kan zijn. Voor de Nederlanders lijkt het meer een "alles of niets"-regel te zijn, waarbij de koppeltekens zij vermijden. Een woord wordt in hun ogen of aan, of uit elkaar geschreven, zonder mogelijke tussenoptie.

De vertalers lijken wat minder creatief met de spelling om te gaan, terwijl het juist de leraren zijn die meer met de regels moeten werken. Een vertaler hoeft niet per se te weten waarom je een bepaald woord zus of en zo schrijft, maar hij moet het wel kunnen. Van een leraar Nederlands verwacht je dat hij ook kan uitleggen waarom de taal zo werkt. In dat opzicht vind ik de foute antwoorden bij de rondetafelvraag eigenlijk wel enigszins beschamend.

Tot nadenken dwingt ook de vraag waarom leraren Nederlands geneigd zijn om in contact met de mensen die Nederlands leren, over te gaan naar het Engels. Door een dergelijke handeling lijken ze naar mijn mening zelf in twijfel te trekken waar ze beroepshalve mee bezig zijn.

Uit het minionderzoek in zijn geheel blijkt echter een vrij tolerante en open stelling van de respondenten ten opzichte van zichzelf en de anderen. Het gaat niet zo ver dat er voor een totale spellingvrijheid wordt gepleit, wel vinden de respondenten het niet wezenlijk erg als er tegen de spelling wordt gezondigd. Dit is in zoverre positief dat het taalgebruik wat ruimte laat voor taalveranderingen, aan de andere kant leidt het echter tot de vraag of de mensen die met het Nederlands werken, toch niet wat strenger zouden moeten zijn ten opzichte van de materie waar ze hun brood mee verdienen. Als we dit pad blijven bewandelen, is er op den duur nauwelijks iemand nog die voor de Nederlandse taal blijft zorgen. En dan zijn er geen leraren Nederlands en nauwelijks nog vertalers nodig.

\section{BIBLIOGRAFIE}

IVN. $20^{\mathrm{e}}$ Colloquium Neerlandicum, colloquium.ivn.nu/aanleveren-bijdrage-5. Laatst geraadpleegd op 30.09.2019.

Kollewijn, Roeland Anthonie. Onze lastige spelling. Een voorstel tot vereenvoudiging. Amsterdam, H. Gerlings, 1891. Oorspronkelijk afgedrukt in Vragen van den Dag, vol. 10, 1891. 
Nederlandse Taalunie. Het Groene Boekje. Woordenlijst Nederlandse Taal. Utrecht/Antwerpen, Van Dale Uitgevers, 2015.

Taaladviesdienst Gennootschap Onze Taal. Spellingwijzer Onze Taal. Houten, Prisma, 2015.

\title{
BĘDZIESZ MIŁOWAŁ BŁĘDY INNYCH LUDZI! \\ TOLERANCJA DLA ZMIAN W JĘZYKU I BŁĘDÓW JĘZYKOWYCH
}

$$
\text { Streszczenie }
$$

Niniejszy esej to apel o bardziej staranny język, zwłaszcza do nauczycieli i tłumaczy języka niderlandzkiego. Zwłaszcza pisownia jest, jak się okazuje, ciągle poważnym problemem, i to nie tylko dla osób uczących się języka niderlandzkiego jako drugiego albo obcego. Niniejszy esej porusza problematykę złożeń i błędów, jakie popełniane są przy pisaniu łącznym lub rozdzielnym tychże złożeń przez osób zawodowo zajmujących się językiem niderlandzkim.

Słowa kluczowe: ortografia; Kollewijn; złożenia; błędy ortograficzne; ankieta.

\author{
YOU WILL CHERISH OTHER PEOPLE'S LANGUAGE ERRORS! \\ TOLERANCE FOR LANGUAGE CHANGES AND SPELLING ERRORS
}

Su m m a r y

This essay is a plea for more careful use of Dutch language, in particular by translators and teachers of Dutch. In particular, the spelling always proves to be a difficult stumbling block, and not just for second-language or foreign-language learners. The essay examines the problem of compound words and mistakes made by professional language practitioners of Dutch when writing these words or not.

Key words: spelling; Kollewijn; compound words; errors; survey. 